\title{
APLICAR OU NÃO APLICAR, EIS A QUESTAO: O DESENVOLVIMENTO SUSTENTÁVEL COMO SOLUÇÃO DA ANTINOMIA NA APLICAÇÃO DO NOVO CÓDIGO FLORESTAL
}

\begin{abstract}
APPLY OR NOT TO APPLY, THAT IS THE QUESTION: SUSTAINABLE DEVELOPMENT AS SOLUTION TO THE ANTINOMY ABOUT THE APPLICATION OF THE NEW FOREST CODE
\end{abstract}

${ }^{1}$ Rafael Antonietti Matthes

\section{RESUMO}

Partindo-se da premissa constitucional brasileira, por meio da qual, o desenvolvimento econômico, assim como o desenvolvimento social, deve primar pela manutenção da qualidade ambiental para as atuais e futuras gerações (artigo 225, caput), o presente estudo sugere um possível indicador para solucionar a antinomia relacionada à aplicabilidade ou não do Novo Código Florestal (Lei 12.651 de 25 de maio de 2012) aos termos de ajustamento de condutas firmados antes de sua vigência, cujas obrigações pactuadas devem ser cumpridas após a sua vigência. Aplicar ou não aplicar, eis a questão. Se de um lado, postulam-se a favor da tese da vedação ao retrocesso ambiental, de outro, destaca-se a concessão de incentivos como propulsão de condutas protetivas e a factual efetividade social da norma agora vigente. Utilizando-se dos métodos de abordagem dialético e sistêmico, com apontamentos empíricos, elenca-se o direito fundamental ao desenvolvimento sustentável como responda ao contraste da linguagem jurídica indicada no problema metodológico.

Palavras-chave: Termos de compromisso, Desenvolvimento sustentável, Código florestal, Aplicabilidade, Antinomia

\begin{abstract}
Starting from the Brazilian constitutional premise, through which, economic development, and social development, should strive for maintaining environmental quality for present and future generations (Article 225, heading), this study suggests a possible indicator to resolve the contradiction related to the applicability or otherwise of the new Forest Code (Law 12651 of May 25, 2012) to the terms of adjustment of conduct signed before its term, which agreed obligations should be implemented upon its validity. Apply or not apply, that is the question. On the one hand, postulate in favor of the fence thesis environmental backlash on the other, there is the provision of incentives such as propulsion protective behaviors and the factual social effectiveness of current regulations now. Using the methods of dialectical and systemic approach, with empirical notes, lists up the fundamental right to sustainable development as respond to the contrast of the legal language indicated in the methodological problem.
\end{abstract}

Keywords: Terms of appointment, Sustainable development, Forest code, Applicability, Antinomy

\footnotetext{
${ }^{1}$ Doutorando em Direito Ambiental pela Pontifícia Universidade Católica de São Paulo - PUC/SP, São Paulo (Brasil). Professor em Direito Ambiental e em Direito Tributário na Universidade Anhanguera (Brasil). E-mail: rafael.matthes@hotmail.com
} 


\section{INTRODUÇÃO}

A consagração do meio ambiente ecologicamente equilibrado como um direito inerente ao ser humano decorre de articulações internacionais especialmente deflagradas após a década de 1960, quando o homem passou a sentir os efeitos nefastos do desenvolvimento econômico desenfreado. A partir de então, vislumbrou-se a internalização daquele direito e todo um arcabouço legal firmou-se com vistas a equilibrar os fatores econômico, social e ambiental.

O ponto de equilíbrio entre tais fatores denota o próprio conceito do princípio do desenvolvimento sustentável, que é reflexo dos longos debates que nortearam as posições antagônicas dos países ricos e pobres antes e durante a Conferência de Estocolmo de 1972 e que foi explicitado no denominado Relatório Brundtland ${ }^{1}$, ou Nosso Futuro Comum, de 1987.

$\mathrm{Na}$ Constituição Federal, tal princípio decorre de uma interpretação conjunta entre os artigos 170, VI e 225, "caput". Trata-se de um elo entre o Título VII, "Da Ordem Econômica e Financeira" e o Título VIII "Da Ordem Social”, que incluí um capítulo próprio relacionado ao meio ambiente. Nesse sentido, clara a correlação dos três fatores pretendida pelo constituinte.

Partindo-se desta concepção, todas as normas jurídicas ou condutadas que tiverem implicações sociais e econômicas, deverão considerar as implicações ambientais, atenuando seus efeitos adversos e/ou incentivando suas externalidades positivas, com vistas a garantir o meio ambiente ecologicamente equilibrado, que é bem de uso comum do povo (art. 225, "caput" da $\mathrm{CF} / 88)$.

A internalização de regras ambientais no Brasil, no entanto, apesar de sua intensificação na segunda metade do Século XX, já era perceptível desde o período colonial. $\mathrm{Na}$ época do descobrimento, vigorava em Portugal as denominadas Ordenações Afonsinas, cujo trabalho de compilação foi concluído no ano de 1446, durante o reinado de Dom Afonso IV. É possível encontrar nestas algumas referências ao meio ambiente, a exemplo do dispositivo que tipificava como crime de injúria ao rei o corte de árvores frutíferas.

As Ordenações Manuelinas foram editadas em 1.521, também contendo dispositivos de caráter ambiental, a exemplo da proibição da comercialização das colmeias sem a preservação das abelhas ou da caça de animais como coelhos, lebres e perdizes com

\footnotetext{
${ }^{1}$ Nome conferido em homenagem à primeira-ministra da Noruega, Gro Harlem Brundtland, que chefiou a Comissão Mundial sobre o Meio Ambiente e Desenvolvimento organizada pela Organização das Nações Unidas para estudar o assunto (GRANZIERA, 2009, p. 33).
} 
instrumentos que pudessem denotar crueldade. A tipificação do corte de árvores frutíferas passou a ser punida com o degrado para o Brasil quando a árvore abatida tivesse valor superior a trinta cruzados.

As Ordenações Filipinas, editadas durante o período em que o Brasil passou para o domínio espanhol, proibiam que jogassem na água qualquer material que pudesse matar os peixes e suas criações ou que sujasse os rios e as lagoas. A tipificação de árvores frutíferas é mantida, prevendo-se como pena o degredo definitivo para o Brasil o corte das árvores.

Durante o Brasil Colônia, foram editadas as primeiras ordens reais envolvendo matéria florestal. Mais especificamente, em 1698, a Coroa Portuguesa proibiu a criação de sesmarias em áreas que pudessem fornecer matéria-prima e somente os governadores, devidamente assessorados, podiam autorizar a supressão de vegetação. A preocupação principal era assegurar madeira naval à Coroa Portuguesa (DEAN, 2011, p. 151).

$\mathrm{Na}$ época, as reservas florestais foram criadas visando à manutenção de suprimento e, portanto, revestidas de caráter econômico. Como consequência, um sexto das propriedades, ocupadas por florestas, deveriam ser preservadas para eventual corte necessário em atendimento às demandas de Portugal.

No ano de 1.802, por recomendação de José Bonifácio, foram baixadas as primeiras instruções para reflorestar a costa brasileira. Em 1.808, foi criado o Jardim Botânico do Rio de Janeiro, como uma área de preservação ambiental, considerada nossa primeira unidade de conservação, destinada a preservar espécies e estimular estudos científicos. Em 1.809, D. João VI expediu a Ordem que prometia a liberdade aos escravos que denunciassem contrabandistas de pau-brasil.

Já por meio de um Decreto, de 3 de agosto de 1.817, proibia-se o corte de árvores nas áreas circundantes do rio Carioca, no Rio de Janeiro. Em 1830, o primeiro Código Criminal tipificou como crime o corte ilegal de madeira.

O Código Civil de 1.916 possibilitou uma legislação ambiental mais completa, no qual os recursos ambientais como a água, a fauna e a flora passaram a ser tratados com maior especificidade sendo regidos por uma legislação diferenciada, impossibilitando a articulação entre cada um desses elementos.

O primeiro Código Florestal brasileiro foi o Decreto 23.793/34 revogado apenas em 1965, por meio da Lei 4.771. À época, evidentemente, o legislador não considerava a variável sustentabilidade quando da promulgação das leis. A redação desta norma tornou-se retrograda, quando os países passaram a interpretar o meio ambiente dentro de uma equação com três fatores. 
Por isso mesmo, a Lei 4.771/65 sofreu alteração por meio de sucessivas emendas, até que, em 2012, após quase uma dezena de anos de tramitação no Congresso Nacional, foi aprovada a Lei 12.651/12, o Novo Código Florestal, que introduziu novas regras e parâmetros relacionados à proteção das florestas brasileiras.

Com a sua promulgação, a "novel” legislação inaugurou grande debate em torno de sua constitucionalidade. De um lado, parte da população brasileira pugnando pela sua não vigência, baseada na tese da vedação ao retrocesso ambiental. De outro, parte da população defendendo sua aplicabilidade, na resolução das celeumas jurídicas florestais.

Atualmente, encontram-se pendentes de julgamento perante o Supremo Tribunal Federal (STF), três ações direitas de inconstitucionalidade ${ }^{2}$ ajuizadas em face da referida norma jurídica, sem qualquer manifestação liminar, cabendo às demais esferas judiciais determinar sua aplicabilidade em território nacional.

A dificuldade de aplicação - e o objeto da presente pesquisa segue nesse sentido, não está relacionada aos eventos futuros, já que, como visto, não há qualquer manifestação do STF. Está relacionada sim aos eventos passados, cujos efeitos se estenderam até a promulgação da nova lei.

A título de exemplo, têm-se os termos de ajustamento de condutas (TACs), que em grande parte foram firmados sob a vigência da lei revogada e seu cumprimento observado na vigência da lei atual. O problema metodológico desta pesquisa relaciona-se exatamente à resolução da antinomia: lei revogada ou lei vigente?

Para tanto, no primeiro capítulo, será apontada uma visão sistêmica que norteia a aplicação das normas ambientais e que é própria do denominado Estado de Direito Ambiental (BIANCHI, 2010, p. 80). Por se tratar de um direito fundamental proveniente da esfera internacional, sua percepção deve conceber outros fatores, como o desenvolvimento econômico e social.

As diretrizes relacionadas à proteção das florestas serão analisadas no segundo capítulo, quando será possível observar a superação do modelo de primazia das normas de comando e controle, para um modelo de incentivo às condutas protetivas, em estrita observância a outro princípio do direito ambiental denominado protetor-recebedor.

\footnotetext{
${ }^{2}$ A Procuradoria Geral da República interpôs três Ações Diretas de Inconstitucionalidade autuadas sob os $\mathrm{n}^{\mathrm{o}} \mathrm{s}$. 4901, 4902 e 4903, com pedido de liminar, contra os dispositivos da Lei $\mathrm{n}^{\circ} 12.651$, de 25 de maio de 2012, bem como as alterações nela promovidas pela Lei $\mathrm{n}^{\circ}$ 12.727, de 17 de outubro de 2012, sendo que, até a presente data, não houve julgamento.
} 
Com as premissas dialéticas e sistêmicas traçadas, serão então abordados, empiricamente, os resultados que demonstram o atual estágio do diálogo das normas jurídicas com os seus destinatários e a concepção de uma visão socioambiental na agricultura.

Os elementos observados demonstrarão que a norma florestal vigente garante equilíbrio entre os fatores ambiental, econômico e social, devendo, portanto, ser aplicada, quando diante da antinomia entre o revogado e o vigente.

\section{A CONSTItUiÇÃo FEDERAL DE 1988 E A FORMAÇÃO DO ESTADO DE DIREITO AMBIENTAL BRASILEIRO: UMA EVOLUÇÃO DAS CONFERÊNCIAS INTERNACIONAIS E A CONSAGRAÇÃO DO PRINCÍPIO DO DESENVOLVIMENTO SUSTENTÁVEL}

Expressões como efeito estufa, poluição, degradação da camada de ozônio, degelo de calotas polares e desaparecimento de cidades litorâneas, como Veneza, estão cada vez mais frequentes nos noticiários matinais, nos discursos dos grandes líderes e até mesmo nos desenhos animados.

Há alguns anos, tais fenômenos eram apenas uma hipótese. Atualmente, após diversos estudos científicos, tornou-se uma realidade. Para se ter uma ideia, há constatações de que "o planeta jamais se aqueceu tão rápido quanto nos últimos 25 anos" (PEARCE, 2002, p. 4).

Esses graves problemas, no entanto, conforme explicitado por José Eduardo Ramos Rodrigues, na obra organizada pelos professores doutores Cristiane Derani e José Augusto Fontoura Costa (2001, p. 7), “não põe em risco apenas interesses pecuniários individuais ou de determinadas classes sociais de alguns países, (...) mas a sobrevivência de toda a humanidade e da vida como a conhecemos".

A partir do momento em que a sociedade tomou conhecimento dessa natureza transfronteiriça dos danos ambientais, o combate passou a ser de interesse de todos os países soberanos, deixando de ser apenas uma questão local, para se tornar uma preocupação global.

O Direito Internacional, que "tradicionalmente regula, como objetivo central, as relações existentes entre Estados” (DERANI e COSTA, 2001, p. 11), tornou-se, então, um importante sistema regulatório de questões ambientais.

Pode-se dizer, portanto, que neste contexto surgiu uma verdadeira diplomacia ambiental, que, de acordo com DANTAS (2009, p. 54), “abrange as relações internacionais 
cujo centro das atenções é voltado para o meio ambiente". Essa interação entre os sujeitos de direito internacional, no entanto, possui particularidades, já que extrapola a simples relação entre dois ou mais governos oficiais, interagindo com outros atores "como as ONGs, os sindicatos, os movimentos sociais, as associações de moradores, entre outros, produzindo uma revisão de prioridades para a construção de uma diplomacia entre Estados ambientais" (DANTAS, 2009, p. 56).

O caráter cooperativo do direito internacional e a emergência de uma proteção global do assunto levou os estados soberanos a se reunirem por diversas vezes em conferências internacionais ambientais organizadas sob os auspícios da Organização das Nações Unidas, dentre as quais, se destacam a Conferência de Estocolmo de 1972, a Conferência do Rio de 1992, a Conferência de Johanesburgo de 2002 e a Conferência do Rio de 2012.

A partir do contexto internacional despontaram os princípios do direito ambiental moderno, que deram base ao Estado de Direito Ambiental brasileiro especializado com a promulgação da Constituição Federal de 1988.

Dentro desta contextualização, merece destaque o ano de 1987, cujas influências impactaram diretamente no ordenamento jurídico brasileiro atual.

Foi neste ano, que a Comissão Mundial sobre o Meio Ambiente e Desenvolvimento entregou à Assembleia-Geral da ONU, um relatório denominado Nosso Futuro Comum ou Relatório Brundtland, que afirmava a necessidade de entrar em uma nova era de crescimento econômico apoiado em práticas que conservassem e expandissem a base dos recursos ambientais.

Neste relatório, restou consagrada a ideia da sustentabilidade, ou seja, o desafio global de proteção ao meio ambiente não mais podia se dissociar das questões relativas ao desenvolvimento econômico e social. Por meio desse relatório, a expressão desenvolvimento sustentável restou assim conceituada ${ }^{3}$ :

Em essência, o desenvolvimento sustentável é um processo de transformação no qual a exploração dos recursos, na direção dos investimentos, a orientação do desenvolvimento tecnológico e a mudança institucional se harmonizam e reforçam o potencial presente e futuro, a fim de atender às necessidades e aspirações humanas.

De acordo com Granziera (2011, p. 44), o relatório teve o mérito “de explicar a opinião de pessoas de diversos países, que se manifestaram, em audiências públicas, sobre os mais variados temas relacionados ao meio ambiente e ao desenvolvimento".

3 COMISSÃO MUNDIAL SOBRE MEIO AMBIENTE E DESENVOLVIMENTO. Nosso Futuro Comum. $2^{\mathrm{a} e d . ~ R i o ~ d e ~}$ Janeiro: FGV, 1991, p. IX). 
Em uma sociedade globalizada, os constantes e crescentes desafios emergentes demonstram a preocupação essencial com a relação entre o humano e a natureza. Basta navegar um pouco pela internet, ligar o rádio ou ler um jornal: há um bombardeio de notícias, projetos, informações, tratados, decretos, um ilimitado espaço reservado à conscientização social sobre a necessidade de harmonizar homem e natureza.

A preocupação tornou-se necessidade à medida que ações e reações se sucederam continuamente. Hoje, não é mais segredo que um ruflar de asas de uma borboleta pode provocar um furacão, como pertence ao senso comum a sabedoria de que o uso do antibiótico indiscriminadamente pode ser o responsável por uma epidemia.

Muito mais do que preocupação, o Relatório Brundtland impôs, a partir de então, um paradigma, uma filosofia de vida, uma visão de mundo diferente, um pensamento capaz de enxergar o mundo em sua complexidade,

Os seres humanos são sujeitos ativos em um universo mutante, cada vez mais interdependente e é nesse universo que a soberania da vida ecoa: sujeitos únicos, com biografias individuais, mas ao mesmo tempo coletivos, filhos da mesma Terra, inseparáveis da mãe natureza e da energia que os faz vivos.

Nesse sentido, Morin (2001, p.78). explica que o homem possui em si mesmo recursos criativos inesgotáveis o que permite ao mundo:

(...) a esperança de vislumbrar para o terceiro milênio a possibilidade de nova criação, cujos germes e embriões foram trazidos pelo século XX: a cidadania terrestre. E a educação, que é ao mesmo tempo transmissão do antigo e abertura da mente para receber o novo, encontra-se no cerne dessa nova missão.

Para o autor, todos os humanos, desde o século XX, vivem os mesmos problemas fundamentais e estão unidos na mesma comunidade de destino planetário. Aprender a estar aqui, no planeta, significa aprender a comungar, a ser terrenos e a educação do futuro deverá ensinar a ética da compreensão planetária.

Essa consciência da complexidade humana, da inseparabilidade homem e natureza, não é um princípio a ser instaurado, mas a ser conquistado, em suas identidades. Uma conquista contínua, trabalhada e orientada pelas mãos da educação e da sustentabilidade.

Em vista de tal panorama, o legislador constituinte de 1988 pôde, então, verificar "que o crescimento das atividades econômicas merecia um novo tratamento. Não mais poderíamos permitir que elas se desenvolvessem alheias aos fatos contemporâneos", já que "numa 
sociedade desregrada, à deriva de parâmetro de livre concorrência e iniciativa, o caminho inexorável para o caos ambiental é uma certeza” (FIORILLO, 2010, p. 86).

Visando garantir um equilíbrio entre os pilares econômico, social e ambiental, o constituinte brasileiro indicou, dentre os próprios objetivos da República Federativa do Brasil apontados no artigo $3^{\circ}$, a persecução do desenvolvimento e do bem-estar da sociedade. Bemestar que, para ser alcançado, deve resguardar o "bem de uso comum do povo", ou seja, o meio ambiente ecologicamente equilibrado, conforme redação do artigo 225.

Para a Carta Magna, o desenvolvimento sustentável além de ser um princípio norteador do direito ambiental e da ordem econômica, concretiza um objetivo do país, que deverá ser alcançado e almejado por toda a sociedade brasileira.

Em assim sendo, a aplicação das normas ambientais infraconstitucionais pressupõe o respeito à regra maior da sustentabilidade, garantindo-se a qualidade ambiental para as presentes e futuras gerações, sem se olvidar dos princípios da livre inciativa e concorrência, próprios de uma sociedade capitalista.

Conforme indicado por Patrícia Bianchi (2010, p. 88), a eficácia das normas ambientais introduzidas no ordenamento jurídico pressupõe a análise de um sistema formado por princípios relacionados à proteção do meio ambiente. Trata-se de uma visão holística, em que há mudança de paradigma das "partes para o todo" resultando em "mudança de objetivos para relações".

Mais do que norte para aplicação das regras ambientais, a sustentabilidade deve ser considerada para todas as outras normas que impliquem efeitos sociais e econômicos, em razão do seu caráter transversal.

Como ensina a professora Cristiane Derani (2009, p. 66), em razão de seu caráter teleológico, podem-se ter normas de direito ambiental que são destinadoras de regras originalmente pertencentes a determinados outros ramos do direito. "Este é o movimento do direito ambiental, um direito transversal".

A sustentabilidade, como regra de direito ambiental, passa por todo ordenamento jurídico, não lhe cabendo uma delimitação rígida e estática. A ela é característico o movimento próprio da sociedade que integra.

Evidencia-se, portanto, que o Estado brasileiro inaugurado com a promulgação da Carta de 1988 configura um verdadeiro Estado de Direito Ambiental, no qual se persegue um equilíbrio constante, em busca de desenvolvimento e bem-estar social. 


\section{ORDENAMENTO JURÍDICO FLORESTAL BRASILEIRO}

Após algumas décadas de total liberalismo oligárquico, o Brasil pós-revolução de 30, caracterizou-se pelo intervencionismo estatal em áreas econômicas essenciais para o desenvolvimento do país. Foi durante este período, que setores como mineração, recursos hídricos e florestas passaram a ser regulamentados pelas seguintes normas gerais e abstratas: Código de Minas (Decreto-lei 1.985/40) Código de Águas (Decreto 24.643/34) e Código Florestal (Decreto 23.793/34).

Apesar de regulamentos esparsos como visto na introdução, o patrimônio florestal, a partir de 1934, ganhou contornos e diretrizes próprias, cujos efeitos impactaram diretamente no setor agrícola e são perceptíveis no ordenamento atual, por servir de base aos códigos florestais posteriores.

A natureza difusa do direito ao patrimônio florestal evidenciava-se já no primeiro artigo, indicando que as florestas existentes no território nacional constituíam bem de interesse comum a todos os habitantes do país, constituindo, por isso, uma limitação ao direito de propriedade.

As então chamadas florestas protetoras (atuais áreas de preservação permanente), remanescentes, modelo e de rendimento existentes no país passaram a ser resguardadas pelo então Código Florestal, que limitava a utilização destas áreas. Para se ter uma ideia, desde que reconhecida a necessidade ou a conveniência, as florestas remanescentes existentes na propriedade poderiam ser objeto de desapropriação pelo governo federal ou local (art. 12). Um verdadeiro embrião para as atuais unidades de conservação.

A discricionariedade e a conveniência do Poder Público permeavam diversos preceitos. Para se ter uma ideia, se a autoridade florestal julgasse necessário o reflorestamento dentro de uma propriedade privada, esta poderia ser desapropriada, total ou parcial, para aquele fim, salvo se o proprietário consentisse e permitisse que Fazenda Pública, ou ele próprio, fizesse tal adequação (art. 13).

Merece destaque, também, o direito de preferência do Poder Público na aquisição de propriedades declaradas de interesse do patrimônio florestal. Direito que deveria ser exercido no prazo de 90 dias da ciência da alienação ou da transcrição no Registro de Imóveis, sem prejuízo da desapropriação por utilidade pública (art. 16).

Apesar de não se falar em reserva legal, naquele período, o Decreto limitava o abatimento de vegetação existente na propriedade em até três quartas partes, não se podendo utilizar a propriedade integralmente na produção agrícola (art. 23). 
Apesar de seu espírito de norma de comando e controle, já que além das diversas proibições, o Decreto regulamentava a criação de uma polícia florestal e estipulava crimes, contravenções e infrações administrativas, é perceptível a inserção de incentivos às condutas protetivas ao meio ambiente, como, por exemplo, a exclusão da base de cálculo dos impostos, das áreas de florestas existentes no interior da propriedade (art. 17).

Tal Decreto vigorou no país, até o ano de 1965, quando foi promulgada, então, a Lei 4.771. A década de 1960, foi um período de intensa movimentação internacional em prol de uma agenda relacionada ao meio ambiente, tendo em vista a deflagração de catástrofes naturais ${ }^{4}$.

A pequena propriedade rural ou posse rural familiar recebeu contornos legais próprios, diferenciando-a das demais propriedades, em razão da peculiaridades relacionadas à exploração de subsistência.

Durante sua vigência, foram descritos os conceitos de área de preservação permanente. “área protegida (...) com a função ambiental de preservar os recursos hídricos, a paisagem, a estabilidade geológica, a biodiversidade, o fluxo gênico de fauna e flora, proteger o solo e assegurar o bem-estar das populações humanas" e de reserva legal (art. $1^{\circ}$, I e II):

Área localizada no interior de uma propriedade ou posse rural, excetuada a de preservação permanente, necessária ao uso sustentável dos recursos naturais, à conservação e reabilitação dos processos ecológicos, à conservação da biodiversidade e ao abrigo e proteção de fauna e flora nativas.

Naquele período, portanto, as áreas de preservação permanente não poderiam ser computadas para fins de reserva legal. Contudo, em 2001, adveio a Medida Provisória 2.16667, alterando tal conceito, permitindo o computo desde que este não implicasse em conversão de novas áreas para o uso alternativo do solo, e desde que a soma da vegetação nativa em área de preservação permanente e reserva legal não excedesse a oitenta por cento da propriedade rural localizada na Amazônia Legal; cinquenta por cento da propriedade rural localizada nas demais regiões do País; e vinte e cinco por cento da pequena propriedade (art. $16, \S 6^{\circ}$ ).

Diferentemente do código anterior, a reserva legal passou de uma quarta parte de toda e qualquer propriedade, para oitenta por cento, na propriedade rural situada em área de floresta localizada na Amazônia Legal; trinta e cinco por cento, na propriedade rural situada em área de cerrado localizada na Amazônia Legal; vinte por cento, na propriedade rural situada em área de floresta ou outras formas de vegetação nativa localizada nas demais

\footnotetext{
${ }^{4}$ Para se ter uma ideia da preocupação deflagrada na época, no final da década de 60, o Clube de Roma solicitou um parecer sobre a questão ambiental ao Massachusetts Institute of Technology (MIT). Este, por meio de uma equipe liderada por Donella Meadows, apresentou o chamado Relatório Meadows, que dentre outros pontos, explicou que a atividade humana se desenvolve muito mais rapidamente que a capacidade da Terra para produzir seus recursos.
} 
regiões do País; e vinte por cento, na propriedade rural em área de campos gerais localizada em qualquer região do País (art. 16).

Ainda sobre a reserva legal, a lei vigente determinava que a área de reserva legal deveria ser averbada à margem da inscrição de matrícula do imóvel, no registro de imóveis competente, vedando-se a alteração de sua destinação, nos casos de transmissão, a qualquer título, de desmembramento ou de retificação da área (art. 16, $8^{\circ}$ ).

Com primazia pelas regras de comando em controle, a lei, a exemplo do decreto antecessor, prescrevia condutas criminais e infracionais relacionadas ao patrimônio florestal. Era considerada pelos proprietários rurais da época, uma norma de difícil cumprimento, o que resultou na jurisdicionalização de diversos procedimentos instaurados com vistas à apurar responsabilidade penal, cível e administrativo dos proprietários rurais.

A regularização ambiental das propriedades, especialmente a averbação da reserva legal, não era interessante para os proprietários rurais, seja pela burocracia envolvida, sejam pelos autos custos relacionados à regularização e à diminuição da área de produção. As multas, cujos valores não eram demasiados autos, não superavam a perspectiva de lucro, de modo que a norma jurídica vigente não alcança seus destinatários de modo satisfatório.

Inúmeras ações civis públicas foram, então, ajuizadas, após a instauração de longas investigações perpetradas em sede de inquérito civil. No âmbito administrativo, os órgãos do Sistema Nacional do Meio Ambiente (SISNAMA) passaram a aplicar multas e apurar condutas infracionais, ensejando, inclusive, a instauração de inquéritos policiais e de ações criminais pelo aparato policial.

O tempo comprovou o fracasso das medidas de comando e controle amplamente relacionadas na Lei 4.771/65 no cumprimento das obrigações ambientais. O dilema campo e meio ambiente foi acirrado. Havia uma lei, cujos destinatários se recusavam a cumprir.

Por outro lado, os riscos decorrentes dos provimentos jurisdicionais e das multas administrativas induziram, em parte, a perda de competitividade da lavoura brasileira no mercado internacional ${ }^{5}$.

Neste período, visando minimizar os riscos, os proprietários rurais firmaram termos de ajustamento de condutas, nas esferas cível e administrativa. As obrigações estipuladas, no entanto, eram complexas e custosas sendo que, na maioria dos casos, os proprietários não logravam cumprir os acordos no período ali previsto.

\footnotetext{
Tal informação é respaldada pelos números calculados pelo Centro de Estudos Avançados em Economia Aplicada ESALQ/USP, com o apoio financeiro da Confederação da Agricultura e Pecuária do Brasil (CNA), que demonstram que o PIB do agronegócio sofreu pequenas variações para cima e para baixo, mantendo-se constante no período de 1994 a 2014. In: http://www.cepea.esalq.usp.br/pib/ - visualizado em 28.07.2015.
} 
Após anos de tramitação no Congresso Nacional, foi promulgada a Lei 12.651/12, que revogou a Lei 4.771/65 e inseriu novas diretrizes no ordenamento jurídico florestal.

Tal norma, diferentemente da sua antecessora, pressupõe respeito às regras que lhe são superiores, ou seja, aos princípios constitucionais, como o princípio do desenvolvimento sustentável, garantindo desenvolvimento econômico e social e a proteção da qualidade ambiental para as presentes e futuras gerações, como determinado no "caput" do artigo 225 da CF/88. Nas palavras de Paulo de Barros (2013, p. 222):

Sem hierarquia não há sistema de direito, pois ninguém poderia apontar o fundamento de validade das unidades componentes, não se sabendo qual deva prevalecer. Uma regra há de ter, para desfrutar de juridicidade, seu fundamento em outra que lhe seja superior (...) Daí ser possível afirmar, peremptoriamente, que o princípio da hierarquia é um axioma.

Dentre as principais inovações introduzidas pelo Novo Código, está a primazia pelo incentivo das condutas protetivas, em detrimento das normas de comando e controle presente na legislação anterior.

É certo que a manutenção de área com cobertura de vegetação nativa, a título de reserva legal e de preservação permanente, persistiram no ordenamento atual, contudo o procedimento para regularização foi modernizado e facetado, de modo que a lei passou a alcançar os seus destinatários.

Foi criado, por exemplo, o Cadastro Ambiental Rural (CAR), um registro público eletrônico de âmbito nacional, obrigatório para todos os imóveis rurais, com a finalidade de integrar as informações ambientais das propriedades e posses rurais, compondo base de dados para controle, monitoramento, planejamento ambiental e econômico e combate ao desmatamento (art. 29). O CAR substitui a malfadada obrigação de averbar a reserva legal na matrícula do imóvel (art. $18, \S 4^{\circ}$ ).

Enquanto perduraram os 45 anos da Lei 4.771/65, pouquíssimos proprietários rurais averbaram suas reservas legais na matrícula do imóvel. Atualmente, passados três anos da nova lei, $57,27 \%^{6}$ de todo o território nacional já está inscrito no CAR e a meta é alcançar $100 \%$ até maio de 2016, em razão do prazo concedido pela lei.

Tal instrumento permitirá que o Ministério do Meio Ambiente (MMA), por meio do Sistema Nacional de Informações sobre o Meio Ambiente (SINIMA), possa, enfim, monitorar todas as áreas rurais brasileiras, garantindo políticas agrícolas eficazes e desenvolvimento sustentável da agricultura brasileira.

\footnotetext{
${ }^{6} \mathrm{In}:$ http://www.mma.gov.br/mma-em-numeros/cadastro-ambiental-rural - visualizado em 28.07.2015.
} 
A implantação do CAR destina-se, dentre outros objetivos, a receber, gerenciar e integrar dados dos imóveis rurais localizados nos Estados, a cadastrar e controlar informações dos imóveis rurais, referentes ao seu perímetro e localização, às áreas de remanescente de vegetação nativa, às áreas de interesse social, às áreas de utilidade pública, de Preservação Permanente, de Uso Restrito, às áreas consolidadas e às Áreas de Reserva Legal, além de permitir o monitoramento, a manutenção, a recomposição, a compensação e a supressão da vegetação nativa e da cobertura vegetal nas Áreas de Preservação Permanente.

O dono de imóvel rural que inscrever sua propriedade no CAR poderá aderir ao chamado Programa de Regularização Ambiental (PRA) do Ministério do Meio Ambiente. Com esta adesão, que se traduz na assinatura de um novo termo de compromisso, as multas aplicadas até 22.07.2008 serão automaticamente canceladas, e o proprietário do imóvel poderá adequar-se à legislação em prazos que podem alcançar até 20 anos, além disso, o proprietário que inscreve sua propriedade no CAR poderá acessar linhas de crédito diferenciadas (art. 78-A).

Verifica-se, portanto, a primazia das regras incentivadoras em detrimento das regras de comando e controle. Em termos ambientais, tem-se a primazia do princípio do protetorrecebedor em detrimento do poluidor-pagador. Os resultados, como visto, são positivos e podem ser obtidos com grande facilidade por qualquer cidadão brasileiro na rede mundial de computadores.

O CAR e o PRA foram regulamentados, respectivamente, pelos Decretos 7.830/12 e 8.235/2014. O prazo para inscrição no CAR passou a contar a partir da sua implantação (art. $29, \S 3^{\circ}$ ), que ocorreu com a publicação da Instrução Normativa $n^{\circ}$ 02/2014 do Ministério do Meio Ambiente, em 06.05.2014.

Outras medidas incentivadoras que merecem destaque são a dedução das Áreas de Preservação Permanente, de Reserva Legal e de uso restrito da base de cálculo do Imposto sobre a Propriedade Territorial Rural - ITR, gerando créditos tributários (art. 41, II, “c”); a isenção de impostos para os principais insumos e equipamentos, tais como: fios de arame, postes de madeira tratada, bombas d'água, trado de perfuração de solo, dentre outros utilizados para os processos de recuperação e manutenção das Áreas de Preservação Permanente, de Reserva Legal e de uso restrito (art. 41, II, “f”) e a dedução da base de cálculo do imposto de renda do proprietário ou possuidor de imóvel rural, pessoa física ou jurídica, de parte dos gastos efetuados com a recomposição das Áreas de Preservação Permanente, de Reserva Legal e de uso restrito cujo desmatamento seja anterior a 22 de julho de 2008 (art. 41, $\S 1^{\circ}$, II). 
Quanto ao cômputo das áreas de preservação permanente na reserva legal, diferentemente da lei revogada, trata-se de regra e não mais de uma exceção. A partir de 2012, é admitido o cômputo das Áreas de Preservação Permanente no cálculo do percentual da Reserva Legal do imóvel, desde que o benefício previsto não implique a conversão de novas áreas para o uso alternativo do solo; a área a ser computada esteja conservada ou em processo de recuperação, conforme comprovação do proprietário ao órgão estadual integrante do SISNAMA; e o proprietário ou possuidor tenha requerido inclusão do imóvel no Cadastro Ambiental Rural - CAR, nos termos da Lei.

O contexto histórico, portanto, permite constatar a evolução das normas florestais brasileiras e a mudança de paradigma na relação das normas com seus destinatários. A lei vigente, apesar de comportar retrocesso, em partes, na proteção do meio ambiente em comparação à norma anterior, se mostra efetiva e permitirá, dentro dos prazos ali previstos, que seus destinatários regularizem seus passivos ambientais alcançando a sustentabilidade como determinado pela $\mathrm{CF} / 88$.

\section{ANTINOMIAS RELACIONADAS À APLICABILIDADE DO NOVO CÓDIGO FLORESTAL}

Para alguns, o Novo Código Florestal representa um retrocesso em relação à proteção do meio ambiente. Em parte, tal argumento está correto, já foi permitida, dentre outras coisas, a diminuição das áreas de reserva legal e de preservação permanente para as pequenas e demais propriedades, desde que a supressão tenha ocorrido até 22 de julho de 2008 (art. 67), bem como, permitiu-se que os proprietários ou possuidores de imóveis rurais que realizaram supressão de vegetação nativa respeitando os percentuais de Reserva Legal previstos pela legislação em vigor à época em que ocorreu a supressão estejam dispensados de promover a recomposição, compensação ou regeneração para os percentuais exigidos nesta Lei. (art. 68).

Contudo, como visto, o Novo Código Florestal garantiu um diálogo entre a norma e seu destinatário, o que não ocorria com a lei revogada, basta analisar os dados trazidos no capítulo anterior.

Tal divergência de ideias ensejou uma situação conflituosa no ordenamento jurídico atual quanto à aplicação da Lei 12.651/12: aplica ou não aplica, eis a questão?

A concretização deste fato se mostra evidente ao se analisar a situação atual dos termos de ajustamento de conduta (TACs) firmados na vigência da lei revogada, cujo cumprimento perdurou até a vigência da lei atual. 
Com a promulgação da lei nova, os proprietários rurais que haviam firmado tais acordos, seja com a promotoria de justiça, em sede de responsabilidade civil, seja com os órgãos administrativos, em sede de responsabilidade administrativa, buscaram o Poder Judiciário para readequar os termos firmados para que sejam cumpridos conforme a lei vigente.

Tal situação foi amparada, inclusive, por meio do Decreto $8.235 / 14$, que em seu artigo 12, explicitou que, "os termos de compromissos ou instrumentos similares para a regularização ambiental do imóvel rural (...) firmados sob a vigência da legislação anterior, deverão ser revistos para se adequarem ao disposto na Lei nº12. 651, de 2012”.

O referido artigo, no entanto, criou uma antinomia no ordenamento jurídico brasileiro: de um lado o direito adquirido, já que os acordos já estavam firmados e homologados, de outro a aplicação imediata da lei nova, em razão do alcance dos efeitos da coisa julgada.

Antinomia, de acordo com Hans Kelsen (1986, p. 157), ocorre quando "existe um conflito entre duas normas, se o que uma fixa como devido é incompatível com aquilo que a outra estabelece como devido e, portanto, o cumprimento ou aplicação de uma envolve, necessariamente ou provavelmente, a violação da outra".

Já para Tárek Moussallem (2005, p. 191):

Em termos simbólicos, há incompatibilidade sempre que a fórmula (Op . - Op) for verdadeira, desde que sejam válidas, no sistema normativo, as respetivas normas "Op" e "-Op"; ou ainda, sempre que a fórmula (Pp . - Pp) for verdadeira, que significa a validade simultânea, no sistema normativo, das normas "Pp" e "-Pp".

Aurora Tomazini $(2009,378)$, por sua vez, relaciona a antinomia a um problema de interpretação, em suas palavras, “a antinomia, assim como a lacuna, também é um problema de interpretação. Depende das valorações atribuídas pelo intérprete quando da construção do sentido dos textos jurídicos". Nesse sentido, necessário verificar se estamos diante de uma antinomia aparente ou de uma antinomia real.

A primeira caracteriza-se pela possibilidade de solução de conflitos por critérios estabelecidos pelo sistema jurídico vigente, ou seja, pode-se aplicar o critério hierárquico, o critério cronológico ou o critério da especialidade. A segunda "aparece quando tais critérios não são suficientes para solucionar o conflito, devendo este ser resolvido por parâmetros ideológicos do aplicador" (CARVALHO, 2009, p. 379). 
A hierarquia é o critério por meio do qual, evidencia-se a superioridade de uma fonte de produção jurídica sobre a outra, ou seja, de acordo com esse critério, uma norma de nível superior deverá prevalecer sobre uma norma de nível inferior, até se alcançar o nível constitucional que é o ponto de chegada do processo de fundamentação jurídica.

A cronologia, por sua vez, relaciona-se ao tempo de existência da norma, ou seja, a norma editada por último prevalece sobre a editada anteriormente. Trata-se da máxima "lex posterior derogat priori". "Partindo-se de uma premissa constitucional do direito, as normas ingressam no sistema quando publicadas, pois é neste momento que se instaura a comunicação jurídica" (CARVALHO, 2009, p. 382).

Por fim, a especialidade indica que a norma específica deve prevalecer sobre a norma geral, "lex specialis derrogat, lex generalis".

Em que pese os três critérios poderem ser aplicados na antinomia apontada no presente trabalho, certo que tais critérios poderão criar novas antinomias, razão pela qual, está-se diante de uma antinomia dita real (quando os critérios existentes no ordenamento não são suficientes para solucionar a antinomia, devendo esta ser resolvida por parâmetros ideológicos do aplicador) (DINIZ, 2003, pp. 26-27).

Para resolver a antinomia em matéria ambiental, um critério que se mostra plausível, é a aplicação dos princípios basilares. Ressalta-se, mais uma vez, que a eficácia das normas ambientais introduzidas no ordenamento jurídico pressupõe a análise de um sistema formado por princípios relacionados à proteção do meio ambiente, como ensinado por Patrícia Bianchi (2010, p. 80).

Dentre os princípios ambientais, destaca-se aquele que respalda não só as questões ambientais, como todo o ordenamento econômico e social brasileiro, conforme previsão contida nos artigos 170 e 225 da Constituição Federal.

Mais que um princípio de direito ambiental, a sustentabilidade é um objetivo da República Federativa do Brasil, um princípio constitucional que, de modo reflexo, se aplica a todos as demais áreas do direito.

Utilizando-se a sustentabilidade como um critério solucionador da antinomia, devese aplicar a lei que ao mesmo tempo respeita o desenvolvimento econômico e social e preserva a qualidade ambiental das presentes e futuras gerações.

Para tanto, além de proteger o meio ambiente de modo eficaz, a norma precisa conversar com seus destinatários, para que não haja qualquer freio ao desenvolvimento econômico e social equilibrado. 
Tal situação, como visto no capítulo anterior, foi alcançada apenas por meio da Lei 12.651/12 que, em três anos em vigor, já conseguiu inserir mais da metade dos proprietários rurais em um cadastro para adequação ambiental de suas propriedades.

A nova lei não só garantiu efetividade ambiental, principalmente a um importância instrumento da Política Nacional de Meio Ambiente (Lei 6.938/81), que é o SINIMA, como também, garantiu incentivos econômicos aos proprietários rurais que cumpriram seus objetivos.

O caráter incentivador de condutas protetivas explicitado pelo Novo Código Florestal e a eficiência empírica demonstrada até a presente data, comprovam que a norma garante a aplicação do princípio do desenvolvimento sustentável na agricultura brasileira, de modo pelo qual, deve ser, então, aplicada com a solução da antinomia.

Tal é, inclusive, o entendimento deste E. STF, prolatado nos autos da ADPF nº. 101DF, STF, Pleno, 24-6-2009, Rel. Ellen Gracie, que afirmou a validade das instruções normativas que proibiam a importação de pneus usados frente às numerosas decisões judiciais que asseguravam a importação aos importadores independentes, o tribunal afirmou que:

\begin{abstract}
O problema a ser aqui enfrentado não se refere à existência de uma coisa julgada, mas ao alcance de seus efeitos, para que se preserve a eficácia circunscrita ao âmbito específico de um caso já transitado em julgado. Assim, a solução da questão perpassa a consideração de que os efeitos da coisa julgada, quanto à autorização judicial de operações de importação de pneus em um determinado processo judicial transitado em julgado, prevalecem tão somente para aquela determinada operação de importação relacionada a determinados bens e realizada num determinado momento. Dessa forma, aplica-se ao caso, de forma analógica, o entendimento jurisprudencial firmado por esta Corte na Súmula 239 que trata da peculiaridade do alcance da coisa julgada em matéria tributária [...] 'Mutatis mutandis', a resolução da questão assemelha-se também à discussão da inexistência de direito adquirido a determinado regime jurídico [...] ante o entendimento de que não se pode alegar, eternamente, direito adquirido a uma determinada forma de regulação estatal de operações de importação (de pneus) que pode mudar conforme as diretrizes político-jurídicas do Estado brasileiro [do voto do Ministro Gilmar Mendes, fls. 269/270].
\end{abstract}

A ementa mereceu a seguinte redação, nessa parte:

[...] 9. Decisões judiciais com trânsito em julgado, cujo conteúdo já tenha sido executado e exaurido o seu objeto não são desfeitas: efeitos acabados. Efeitos cessados de decisões judiciais pretéritas com indeterminação temporal quanto à autorização concedida para importação de pneus: proibição a partir deste julgamento por submissão ao que decidido nesta arguição.

Segundo a decisão, as decisões transitadas em julgado cujos efeitos foram exauridos não são desfeitas, mas os efeitos das decisões judiciais ainda não efetivados se submetem ao novo regramento. Desnecessário dizer que a decisão judicial não é superior à lei, ostentam a mesma hierarquia e a mesma natureza, cada uma em seu campo de atuação. 
Assim, a conclusão a que chegou o Supremo Tribunal Federal (aplicação imediata da decisão judicial então proferida aos efeitos não produzidos das sentenças judiciais transitadas em julgado) se aplica ao caso concreto, em que a nova lei deve ser aplicada aos efeitos não produzidos da sentença transitada em julgado neste processo.

\section{CONCLUSÕES}

Com a promulgação da Lei 12.651/12, criou-se uma antinomia quanto á aplicação da lei atual ou revogada. Os termos de ajustamento de conduta firmados sob a vigência da norma anterior e cumpridos na vigência da lei nova colocaram em evidencia duas posições antagônicas: o direito adquirido e o alcance dos efeitos da coisa julgada.

Durante esta pesquisa, logrou-se demonstrar que a Lei 12.651/12, que revogou expressamente a Lei 4.771/65 e que introduziu o Novo Código Florestal no ordenamento jurídico brasileiro, apresenta resultados empíricos a favor do meio ambiente em pouco mais de três anos de vigência, cumprimento melhor diálogo com os seus destinatários.

Como bem ensina Paulo de Barros (2013, p. 221), o sistema jurídico é concebido como um sistema autorreferencial e autoreprodutivo de atos de comunicação particulares, ou seja, um sistema constituído por eventos comunicativos específicos que, simultaneamente, se autorreproduzem à luz do binário lícito ou ilícito, se articulam recursiva e circularmente entre si, definem as fronteiras do sistema jurídico e constroem seu meio envolvente próprio.

Evidencia-se, portanto, a importância das normas dialogarem com seus destinatários, para que o sistema seja realmente autorreferencial e autoreprodutivo, senão, estar-se diante de normas sem a chamada eficácia social ou efetividade:

\footnotetext{
A eficácia social ou efetividade, por sua vez, diz respeito aos padrões de acatamento com que a comunidade responde aos mandamentos de uma ordem jurídica historicamente dada ou, em outras palavras, diz com a produção das consequência desejadas pelo elaborador das normas, verificando-se toda vez que a conduta prefixada for cumprida pelo destinatário. Indicaremos, portanto, como eficaz aquela norma cuja disciplina foi concretamente seguida pelos destinatários, satisfazendo os anseios e as expectativas do legislador, da mesma forma que inculcaremos de ineficaz aquela outra cujos preceitos não foram cumpridos pelos sujeitos envolvidos na situação tipificada.
}

A Lei 4.771/65, apesar de vigente, não possuía eficácia social, já que os destinatários da norma não cumpriam os seus preceitos, seja pelo alto custo envolvido na regularização ambiental das propriedades, seja pela burocracia envolvida nos trâmites administrativos. 
Dentro deste contexto, a nova lei, cujos resultados parciais já são observados, conforme verificado no capítulo 2, possui não só eficácia social, como também permite o desenvolvimento econômico do setor agrário, em nítido respeito ao princípio do desenvolvimento sustentável.

Utilizando-se tal princípio, que é basilar do próprio direito constitucional brasileiro, como regra para a solução da antinomia envolvendo a aplicação das normas florestais, evidencia-se, como resposta ao problema metodológico, que o Novo Código Florestal deve ser aplicado à coisa julgada firmada antes da publicação da nova lei, cujos efeitos alcançam sua vigência.

\section{REFERÊNCIAS BIBLIOGRÁFICAS}

BIANCHI, Patrícia. Eficácia das normas ambientais. São Paulo: Saraiva, 2010,

CARVAlHO, Aurora Tomazini de. Teoria Geral do Direito: o Construtivismo LógicoSemântico. São Paulo: PUCSP, 2009.

CARVALHO, Paulo de Barros. Direito Tributário: Linguagem e Método. $5^{\text {a }}$ ed. São Paulo: Noeses, 2013.

DANTAS, Juliana de Oliveira Jota. A Soberania Nacional e a Proteção Ambiental Internacional. São Paulo: Verbatim, 2009.

DEAN, Warren. A ferro e fogo: a história e a devastação da Mata Atlântica brasileira. Tradução de Cid Knipel Moreira. São Paulo: Companhia das Letras, 2011.

DERANI, Cristiane e COSTA, José Augusto Fontoura. Direito Ambiental Internacional. Santos: Leopoldianum, 2001.

DERANI, Cristiane. Direito Ambiental Econômico. $3^{\text {a }}$ ed. São Paulo: Saraiva, 2009.

DINIZ, Maria Helena. Conflito de Normas. São Paulo: Saraiva, 2003.

FIORILlo, Celso Antonio Pacheco. Curso de Direito Ambiental Brasileiro. $11^{\mathrm{a}}$ ed. São Paulo: Saraiva, 2010. 
GRANZIERA, Maria Luiza Machado. Direito Ambiental. São Paulo: Atlas, 2009.

KELSEN, Hans. Teoria Geral das Normas. Porto Alegre: Fabris, 1986.

MORIN, Edgar. Os sete saberes necessários à educação do futuro. São Paulo: Cortez; Brasília, DF:UNESCO, 2001.

MOUSSALEM, Tárek Moysés. Revogação em matéria tributária. São Paulo: Noeses, 2005.

PEARCE, Fred. O aquecimento global: causas e efeitos de um mundo mais quente. São Paulo: Publifolha, 2002. 